\title{
Calbindin in Cerebellar Purkinje Cells Is a Critical Determinant of the Precision of Motor Coordination
}

\author{
Jaroslaw J. Barski, ${ }^{1,2}$ Jana Hartmann, ${ }^{3}$ Christine R. Rose, ${ }^{3}$ Freek Hoebeek, ${ }^{4}$ Karin Mörl, ${ }^{1}$ Michael Noll-Hussong, ${ }^{3}$ \\ Chris I. De Zeeuw, ${ }^{4}$ Arthur Konnerth, ${ }^{3}$ and Michael Meyer ${ }^{1,2}$ \\ ${ }^{1}$ Max-Planck-Institute of Neurobiology, D-82152 Martinsried, Germany, ${ }^{2}$ Institute of Ophthalmology, University College London, London EC1V 9EL, \\ United Kingdom, ${ }^{3}$ Institute of Physiology, Ludwig-Maximilians-University of Munich, D-80336 Munich, Germany, and ${ }^{4}$ Department of Neuroscience, \\ Erasmus University Rotterdam, 3000DR Rotterdam, The Netherlands
}

Long-term depression (LTD) of Purkinje cell-parallel fiber synaptic transmission is a critical determinant of normal cerebellar function. Impairment of LTD through, for example, disruption of the metabotropic glutamate receptor- $\mathrm{IP}_{3}$-calcium signaling cascade in mutant mice results in severe deficits of both synaptic transmission and cerebellar motor control. Here, we demonstrate that selective genetic deletion of the calcium-binding protein calbindin D-28k (calbindin) from cerebellar Purkinje cells results in distinctly different cellular and behavioral alterations. These mutants display marked permanent deficits of motor coordination and sensory processing. This occurs in the absence of alterations in a form of LTD implicated in the control of behavior. Analysis of synaptically evoked calcium transients in spines and dendrites of Purkinje cells demonstrated an alteration of time course and amplitude of fast calcium transients after parallel or climbing fiber stimulation. By contrast, the delayed metabotropic glutamate receptor-mediated calcium transients were normal. Our results reveal a unique role of Purkinje cell calbindin in a specific form of motor control and suggest that rapid calcium buffering may directly control behaviorally relevant neuronal signal integration.

Key words: calbindin D-28k; conditional null mutant; Purkinje cell; motor coordination; long-term depression; synaptically evoked calcium transients

\section{Introduction}

One of the hallmarks of cerebellar Purkinje cells is their ability to express a characteristic form of activity-dependent synaptic plasticity named long-term depression (LTD). LTD is induced by the joint activity of afferent climbing fibers (CFs) and parallel fibers (PFs) and represents a persistent reduction of the efficacy of parallel fiber-mediated excitatory postsynaptic potentials (Ito, 1986). A key event in LTD induction is the activation of postsynaptic metabotropic glutamate receptors (mGluRs) (Rose and Konnerth, 2001). Mice null mutant for mGluR1, a subtype of mGluRs that is expressed in Purkinje cells (Martin et al., 1992; Gorcs et al., 1993; Ryo et al., 1993), exhibit severe cerebellar symptoms such as ataxia and motor discoordination and lack LTD (Aiba et al., 1994; Conquet et al., 1994). The behavioral relevance of Purkinje cell mGluR1 for proper cerebellar function was elegantly and unequivocally confirmed by the selective rescue of mGluRs in Purkinje cells of mGluR1 null mutant mice (Ichise et al., 2000), which restored both LTD and locomotor activity.

Further confirmation and extension of these findings came from studies showing that a perturbation of the mGluR1-

\footnotetext{
Received Dec. 6, 2002; revised Jan. 31, 2003; accepted Feb. 5, 2003.

This work was supported by Deutsche Forschungsgemeinschaft Grant SFB391 (to A.K.), Deutsche Forschungsgemeinschaft Grant ME1121/3 (to M.M.), and grants from the Human Frontier Science Program, European Economic Community, and Nederlandse Organisatie voor Wetenschappelijk Onderzoek (to C.I.D.Z.). We thank B. Kunkel, A. Steinberg, and E. Barska for excellent assistance; and Hans Thoenen, Chris Yeo, and Michael Häusser for discussion and critical reading of this manuscript.

Correspondence should be addressed to Dr. Michael Meyer, Division of Molecular Genetics, Institute of Ophthalmology, University College London, 11-43 Bath Street, London EC1V 9EL, UK. E-mail:m.meyer@ucl.ac.uk. Copyright $\odot 2003$ Society for Neuroscience $\quad 0270-6474 / 03 / 233469-09 \$ 15.00 / 0$
}

activated signaling cascade at virtually every level [e.g., G-protein G $\alpha \mathrm{q}$ (Offermanns et al., 1997), phospholipase C $\beta$ (Kano et al., 1998), and $\mathrm{IP}_{3}$ (Matsumoto et al., 1996; Miyata et al., 2000)] results in impaired LTD and disturbed cerebellar motor control. $\mathrm{IP}_{3}$ causes $\mathrm{Ca}^{2+}$ release from intracellular stores (Mikoshiba et al., 1994; Finch and Augustine, 1998; Takechi et al., 1998), and synaptically induced dendritic $\mathrm{Ca}^{2+}$ signaling has been known for a long time to be a critical step in LTD induction (Sakurai, 1990; Konnerth et al., 1992). On the basis of earlier evidence, it seemed that not merely the lack of synaptically mediated $\mathrm{Ca}^{2+}$ signaling in Purkinje cells, but also a change in the temporal dynamics of postsynaptic $\mathrm{Ca}^{2+}$ transients after general genetic deletion of the calcium-binding protein calbindin D-28k (calbindin), might cause impairment of motor coordination (Airaksinen et al., 1997). However, despite the suggestion of an involvement of Purkinje cells, it remained unclear which cell types were responsible for the behavioral phenotype, because calbindin is expressed by many types of neurons throughout the brain (Celio, 1990). Even in the cerebellum, calbindin is expressed abundantly not only in Purkinje cells but also in climbing fibers (Celio, 1990; Scotti, 1995), and previous studies demonstrated that $\mathrm{Ca}^{2+}$ binding proteins influence presynaptic transmitter release (Chard et al., 1995; Klapstein et al., 1998; Caillard et al., 2000). Finally, it was not tested whether the calbindin-mediated change in $\mathrm{Ca}^{2+}$ signaling affected cerebellar LTD. To study the specific role of calbindin in a single defined neuronal cell type, we generated a Purkinje cell-specific calbindin null mutant mouse strain and performed an analysis on the cellular and behavioral level. 


\section{Materials and Methods}

Conditional null mutant mice. A mouse strain carrying a floxed calbindin allele was used (Barski et al., 2002). In brief, a pgk promoter-neo-pA-pgk promoter-TK-pA cassette flanked by loxP sites in the same orientation was inserted into the Eco47III site of a $6 \mathrm{~kb}$ XhoI-SalI genomic fragment (Airaksinen et al., 1997), and a third loxP was ligated into the ClaI site upstream of the first coding exon. ES cell clones were generated in R1 embryonic stem cells (a gift from A. Nagy, University of Toronto, Toronto, Canada), and correctly targeted clones underwent a second electroporation with the Cre expression plasmid pMCCre (a gift from $\mathrm{H}$. Gu and K. Rajewsky, University of Cologne, Cologne, Germany). Clones with the desired recombination were injected into $\mathrm{C} 57 \mathrm{Bl} / 6(\mathrm{C} 57 \mathrm{Bl} /$ 6NCrl BR; Charles River, Sulzbach, Germany) blastocysts. Resulting chimeras were crossed with $\mathrm{C} 57 \mathrm{Bl} / 6$ mice. Animals of heterozygote intercrosses were used for analysis. The Cre transgenic strain used in this study has previously been characterized (Barski et al., 2000); here, we used substrain L7Cre-2.

Western blot and immunohistochemistry. Western blotting was as previously described (Airaksinen et al., 1997) using a mouse monoclonal antibody to calbindin (1:10,000; SWant). For immunohistochemistry (Airaksinen et al., 1997) on 30- $\mu \mathrm{m}$-thick free-floating sections, we used rabbit antibodies to parvalbumin (1:500; SWant) and mouse monoclonal calbindin antibodies (1:500; SWant) together with fluorescein or Texas Red-coupled secondary antibodies (Jackson ImmunoResearch, West Grove, PA). Images were taken on a Leitz DM IRB confocal microscope (Leica, Nussloch, Germany) using the graphics program ImageSpace (Molecular Dynamics, Sunnyvale, CA).

Reverse transcription-PCR. The reverse transcription (RT) reaction was performed on $1 \mu \mathrm{g}$ of total RNA from the indicated brain regions, as described earlier (Barski et al., 2002).

Locomotion analysis. Open-field analysis was performed on the TruScan activity monitor (Coulbourn Instruments), as described (Barski et al., 2000).

The runway and horizontal bar tests were performed essentially as before (Airaksinen et al., 1997). The number of assay days and width of the runway were as indicated. Maximal time on the horizontal bar was $120 \mathrm{sec}$. Data were analyzed with the ANOVA single-factor test.

Compensatory eye movements. Measurement of compensatory eye movements was performed essentially as described before (De Zeeuw et al., 1998a). The eye coil had an outside diameter of $0.5 \mathrm{~mm}$ and was made of 40 windings of $25-\mu \mathrm{m}$ isolated brass wire (resistance, 25-35 $\Omega$ ). A servo-controlled turntable and drum (Benedict) delivered optokinetic and vestibular stimuli. The stimulus paradigms included sinusoidal optokinetic stimulation and sinusoidal table stimulation in the dark and light at frequencies from 0.1 to $1.6 \mathrm{~Hz}$ and with peak velocities from 3 to $96^{\circ} / \mathrm{sec}$. All gain and phase values were analyzed off-line using the CedAnal program for Windows according to standard procedures in our laboratory. Eye movements were recorded from 11 adult recombined and 10 adult control mice.

Electrophysiology in slices and LTD. Whole-cell recordings were obtained from Purkinje cells of $300-\mu \mathrm{m}$ thick cerebellar slices from 18 - to 30-d-old mice. The animals were decapitated after anesthesia with $\mathrm{CO}_{2}$, and the cerebella were rapidly removed and placed in ice-cold artificial CSF composed of (in mM): $125 \mathrm{NaCl}, 2.5 \mathrm{KCl}, 2 \mathrm{CaCl}_{2}, 1 \mathrm{MgCl}_{2}, 1.25$ $\mathrm{NaH}_{2} \mathrm{PO}_{4}, 26 \mathrm{NaHCO}_{3}$, and 20 glucose, bubbled with $95 \% \mathrm{O}_{2}$ and $5 \%$ $\mathrm{CO}_{2}$. After cutting, slices were kept for $45-60 \mathrm{~min}$ at $37^{\circ} \mathrm{C}$ and then for up to $8 \mathrm{hr}$ at $25^{\circ} \mathrm{C}$ until they were used for experiments. Somatic whole-cell recordings were obtained with an EPC8 or EPC9 amplifier (HEKA). PULSE software (HEKA) was used for data acquisition. Pipettes (2-4 $\mathrm{M} \Omega$ resistance) were pulled from borosilicate glass (Hilgenberg) and coated with silicon (RTV 615; GE Silicons). The pipette solution contained (in mM): 148 potassium gluconate, $10 \mathrm{HEPES}, 10 \mathrm{NaCl}, 0.5 \mathrm{MgCl}_{2}$, $4 \mathrm{Mg}$-ATP, and $0.4 \mathrm{Na}_{3}$-GTP, pH 7.3. For $\mathrm{Ca}^{2+}$ imaging experiments, $100 \mu \mathrm{M}$ Oregon green BAPTA-1 (Molecular Probes, Eugene, OR) was added to the pipette solution. During the experiments, the slices were continuously perfused with artificial CSF bubbled with $95 \% \mathrm{O}_{2}$ and 5\% $\mathrm{CO}_{2}$ (at $22-23^{\circ} \mathrm{C}$, except for LTD experiments) containing $10 \mu \mathrm{M}$ bicuculline (Sigma, St. Louis, MO). Synaptic stimulation was performed by using a standard patch pipette filled with $1 \mathrm{~mm} \mathrm{NaCl}$ ( $1 \mathrm{M} \Omega$ resistance) placed in the molecular layer. The stimulus pulse amplitude $(150 \mu \mathrm{sec}$ duration) was 2-20 V for PF stimulation and 20-55 V for CF stimulation. PF-EPSCs were identified by their characteristic features (graded response amplitude and paired pulse depression). Without moving the stimulus pipette, the intensity was increased until a climbing fiber response was observed, distinguished by its all-or-none character and paired pulse depression (Konnerth et al. 1990, 1992), and the CF stimulus threshold was determined. Parallel fibers were stimulated at $0.2 \mathrm{~Hz}$, and EPSCs were recorded in the voltage-clamp mode until a stable baseline amplitude was obtained for at least $10 \mathrm{~min}$. To induce LTD, the stimulus intensity was raised to a value at least $20 \%$ over CF threshold, and 240 stimuli were repeated at $1 \mathrm{~Hz}$ in conjunction with a depolarizing pulse ( $200 \mathrm{msec},-60$ to $0 \mathrm{mV}$ ). After pairing, the stimulus intensity was set to the initial value, and the recording of PF-EPSCs at $0.2 \mathrm{~Hz}$ was resumed for $60 \mathrm{~min}$. Passive membrane properties of Purkinje cells were monitored by applying $3 \mathrm{mV}$ hyperpolarizing pulses. The series resistance was monitored and actively compensated throughout the measurement to $\sim 10-20 \mathrm{M} \Omega$, and only cells fulfilling our stability criteria were used in the analysis (see Fig. 4). The bath temperature was $32^{\circ} \mathrm{C}$.

Calcium imaging. A confocal laser-scanning microscope (Odyssey; Noran), attached to an upright microscope [Axioskop2, 63× water immersion objective, numerical aperture (NA) 0.9; Zeiss, Thornwood, NY) was used to acquire fluorescence images at $30 \mathrm{~Hz}$ in parallel to the wholecell recordings. $\mathrm{Ca}^{2+}$ imaging was started at least $20 \mathrm{~min}$ after establishment of whole-cell configuration.

Full-frame images were recorded at $30 \mathrm{~Hz}$ on an optical disk (TQFH224; Panasonic) using the Image- 1 software ( Universal Imaging Corporation, West Chester, PA) and analyzed off-line with custom-made software on the basis of LABVIEW (National Instruments). $\mathrm{Ca}^{2+}$ transients (see Fig. 5D) were recorded in regions of interest in active dendritic regions. For measurement of calcium transients in dendritic spines, twophoton imaging was performed in parallel to whole-cell patch-clamp recordings. We used a custom-built two-photon laser-scanning microscope on the basis of a mode-locked Ti:sapphire laser system operated at $790 \mathrm{~nm}$ center wave length, $80 \mathrm{MHz}$ pulse repeat, and $<100 \mathrm{fsec}$ pulse width (Tsunami and Millenia, Spectra Physics) and a laser-scanning system (MRC 1024; Bio-Rad, Hercules, CA) coupled to an upright microscope (BX50WI; Olympus Optical, Tokyo, Japan) equipped with a $60 \times$ 0.9 NA water immersion objective (Olympus Optical). To achieve high temporal resolution, fluorescence was acquired in the line scan mode at a sampling rate of $160 \mathrm{~Hz}$ (control animals) or $480 \mathrm{~Hz}$ (recombined) Background-corrected line scan images were analyzed off-line with a custom-written routine in LABVIEW (National Instruments). The $\mathrm{Ca}^{2+}$-dependent fluorescence signals were expressed as increases in fluorescence divided by the prestimulus fluorescence values $\left(\Delta F / F_{0}\right)$ and further analyzed using Igor Pro (Wavemetrics) or Origin (Microcal) software.

\section{Results}

\section{Characterization of Purkinje cell-specific null mutant mice}

For orientation, the targeting strategy for the floxed calbindin allele (referred to as $\mathrm{Calb}^{\text {tm2 }}$ ) (Barski et al., 2002) is depicted in Figure $1 \mathrm{~A}$. Because the properties of the floxed and recombined alleles are critical to the work presented here, we performed additional experiments to this point and repeated some of the earlier work. Western blotting and RT-PCR experiments confirmed our previous conclusion that the introduced loxP sites are without effect on calbindin levels or distribution in homozygous Calb $^{t m 2}$ mice (Fig. 1B). We had previously shown that Calb ${ }^{t m 2} /$ $\mathrm{Calb}^{t m 2}$ mice are also indistinguishable from their wild-type littermates in the open field and runway behavioral assays (Barski et al., 2002). The L7Cre-2 transgenic mouse strain, which expresses Cre recombinase under the control of the Purkinje cell-specific L7/pcp-2 minigene, has previously been shown to allow highly selective and efficient recombination in Purkinje cells (Barski et al., 2000). 


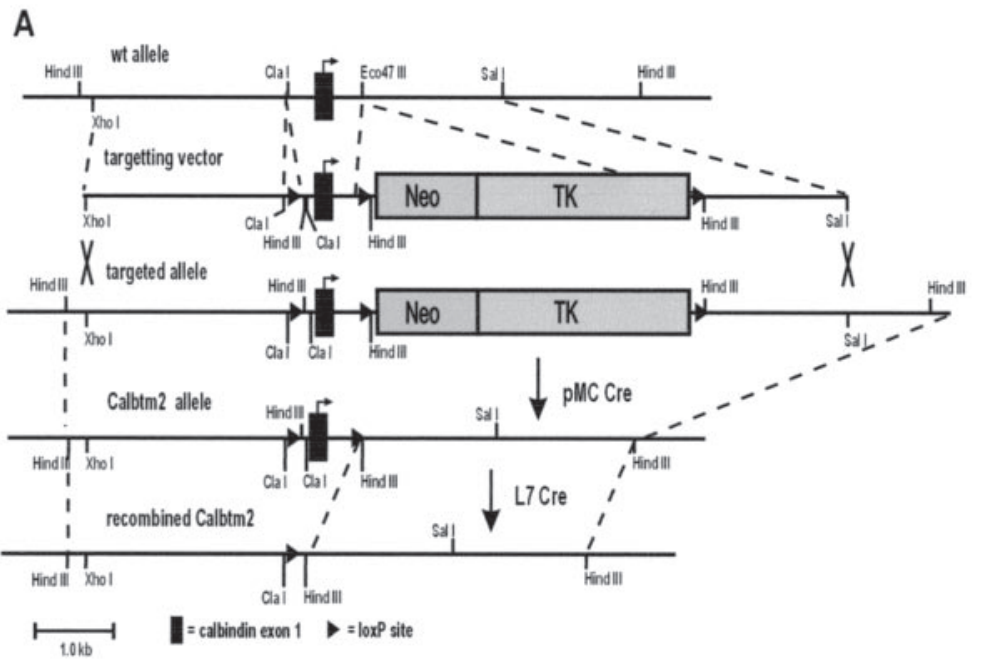

B
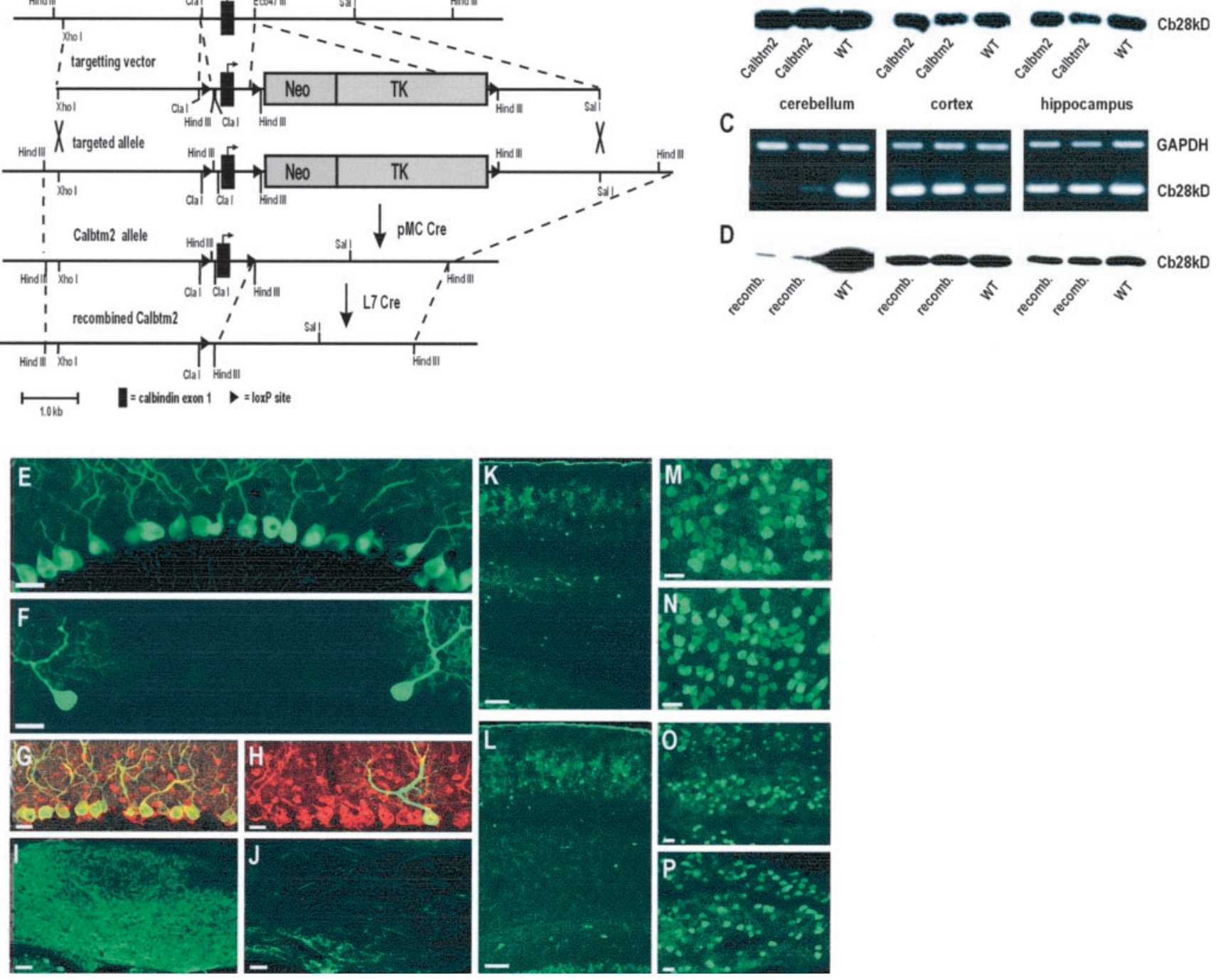

Figure 1. Generation and characterization of the conditional mutant. A, Targeting strategy. B, Western blot of equal amounts of protein from the indicated tissues from Calb ${ }^{\text {tm2 }} / \mathrm{Calb}^{\mathrm{tm} 2}$ and wild-type mice detected by a monoclonal calbindin antibody. C, RT-PCR of calbindin transcripts in cerebellum, cortex, and hippocampus. Glyceraldehyde-3-phosphate dehydrogenase was amplified as an internal control. D, Western blot analysis of calbindin expression (as in $B$ ) of recombined and control mice. Cb28kD, Positions of calbindin protein or amplification product. E- $P$, Localization of calbindin in recombined $(F, H, J, L, N, P)$ and not-recombined $(E, G, I, K, M, O)$ mice by immunohistochemistry using a monoclonal calbindin antibody. E, $F$, Cerebellar cortex; $G, H$, cerebellar cortex double-stained for calbindin (green) and parvalbumin (red); $I, J$, deep cerebellar nuclei; $K, L$, cerebral cortex; $M, N$, striatum; $O, P$, inferior olive. Scale bars: $E-H, M-P, 20 \mu \mathrm{m} ; I, J, 40 \mu \mathrm{m} ; K, L, 80 \mu \mathrm{m}$.

Intercrossing of double heterozygous mice gave offspring at the expected Mendelian ratios, which was divided into two groups. The control group (not recombined) comprises all genotypes lacking either the Call ${ }^{\text {tm } 2}$ or the $L 7 C r e-2$ allele. The recombined group consists of all mice homozygous for the $\mathrm{Calb}^{\mathrm{tm} 2}$ allele combined with one or two L7Cre-2 alleles. Within each group, behavioral, biochemical (besides genotypes), histological, and immunocytochemical assays did not reveal differences between animals. Mice of both groups were similar with respect to growth, life span, and fertility. Tissue-specific recombination was verified by RT-PCR (Fig. $1 C$ ) and Western blotting (Fig. $1 D$ ). In the cerebellum, calbindin transcripts and protein were readily detected in the control group but almost absent in recombined mice. Residual calbindin was estimated to be $<5 \%$ of control levels. No differences were detected in cortex and hippocampus. Cell type specificity was investigated by immunohistochemistry in sagittal brain sections. We found that $<2 \%$ of Purkinje cells of recombined mice displayed residual calbindin immunoreactivity
(Fig. 1E-H; fields selected for a maximum number of notrecombined cells are shown). Purkinje cells of normal morphology could, however, be rendered visible by immunostaining for parvalbumin, another major cytosolic calcium-binding protein of these cells (Fig. 1G,H). Calbindin immunoreactivity was also reduced in basal parts of the cerebellum, where Purkinje cell axons terminate in the deep cerebellar nuclei (Fig. $1 I, J$ ). The presence of few calbindin-positive fibers is consistent with the low number of Purkinje cells in which recombination did not occur. No differences in calbindin immunoreactivity were observed for other brain regions (Fig. $1 \mathrm{~K}-\mathrm{P}$; dentate gyrus and CA1 pyramidal cells; data not shown). Thus, efficient and specific deletion of calbindin from Purkinje cells has been achieved.

\section{Limb coordination}

Our previous work has revealed impaired motor coordination in the general calbindin null mutant mouse (Airaksinen et al., 1997). In that study, however, it could not be tested whether 

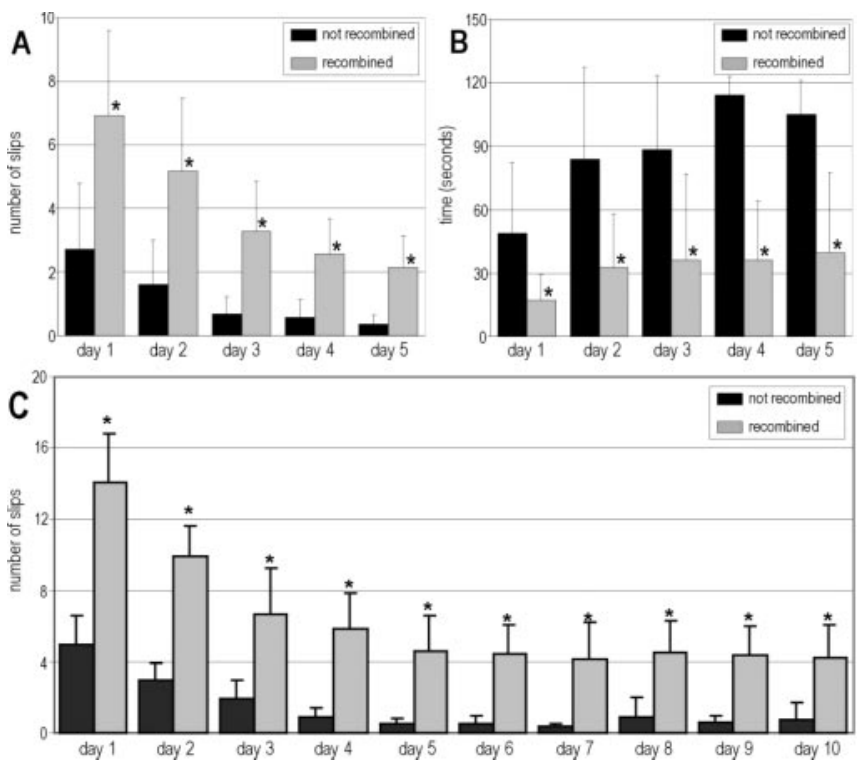

Figure 2. Limb coordination. $A$, Five day runway task on the 2-cm-wide bar (not recombined, $n=19$; recombined, $n=21 ;{ }^{*} p \leq 3.1 \times 10^{-6}$ ). $B$, Balance rod test (not recombined, $n=9$; recombined, $n=7 ;{ }^{*} p \leq 3.2 \times 10^{-2}$ ). C, Ten-day runway task on the 1 -cm-wide bar (not recombined, $n=9$; recombined, $n=10 ;{ }^{*} p \leq 9.2 \times 10^{-5}$ ).

changes in multiple normally calbindin-expressing populations caused these deficits, or whether calbindin is critically required within a single cell type. To resolve this question, we examined motor coordination of Purkinje cell-specific null mutants.

General locomotor abilities and explorative behavior as tested in the open field did not differ between control and Purkinje cell-specific null mutant groups (data not shown). However, severe locomotor deficits in recombined mice were revealed in a standardized limb coordination test in which foot slips were counted during passage over a narrow runway (Airaksinen et al., 1997). Recombined mice made significantly more errors throughout the entire testing period and during prolonged training (Fig. 2A). Although their slip rate decreased during the first days of the test, they never reached the performance levels of controls. Rather, their error rate appeared to asymptotically level off at values clearly higher than those of the control group. Thus, lack of calbindin in Purkinje cells results in a permanent impairment of coordination that cannot be compensated even by prolonged training. Moreover, the deficit was correlated with the difficulty of the task (Fig. 2C). Within groups, decreasing the width of the runway by a factor of two (from 2 to $1 \mathrm{~cm}$ ) resulted in twofold higher initial slip rates, with the recombined group making more errors on both runways than the not-recombined animals. An interesting additional difference became apparent at the end of testing. Control mice reached similar levels of performance irrespective of the width of the runway used, whereas recombined mice made two times more errors on the narrow than on the wide runway. Furthermore, groups differed in their ability to stay on a stationary horizontal bar (Fig. $2 B$ ). Whereas many mice of the not-recombined control group reached the test criterion (120 sec on the horizontal bar) on the fourth day, for recombined animals, only a small increase in the time spent on the bar occurred between days 1 and 3, after which no further improvement was observed.

These experiments show that specific motor deficits are indeed induced by lack of calbindin from a single cell type, the cerebellar Purkinje cell.

\section{Compensatory eye movement}

We sought to further dissect calbindin-dependent motor coordination by measuring optokinetic reflex (OKR) and vestibularocular reflex (VOR) (DeZeeuw et al., 1998a). Both reflexes use sensory information [visual for the OKR and vestibular for the VOR in the dark (VOR-D)] to compensate for movements of visual scene or head. Both types of sensory input act synergistically in the light (VOR-L). The parameters gain and phase are measures for the amplitude and timing of eye movements relative to those of the visual scene or head (Koekkoek et al., 1997).

The gain of the OKR was significantly lower in recombined than control animals at all stimulus frequencies tested (0.1-1.6 $\mathrm{Hz}$; average significance level, $p=0.02$ ), whereas the phase values were not different (Fig. $3 A, B$ ). Similarly, gain but not phase of the VOR-L was significantly reduced at all frequencies $(0.2-1.6 \mathrm{~Hz}$; average significance level, $p=0.03$; Fig. $3 C, D)$. VOR-D parameters were not altered; the average gain and phase values of both animal groups varied from 0.1 to 0.3 and a lead from 123 to $18^{\circ}$, respectively (data not shown). Thus, the motor pathways involved in these cerebellar reflexes seem not affected by loss of calbindin, whereas the visual control of the extent of compensatory eye movement is clearly impaired. This could be because of either an alteration in visual input to Purkinje cells or a problem with Purkinje cell-dependent processing of this input. Because of the specificity of the generated conditional mutation, the former possibility is unlikely. Specifically, an alteration of the properties of retinal bipolar cells, which are known to express $L 7 / p c p-2$ and the Cre transgene used in this study (Barski et al., 2000), can be excluded, because calbindin is not expressed in these cells in mice (Celio, 1990; Pochet et al., 1991). These data show that absence of calbindin from cerebellar Purkinje cells affects eye (as well as limb) coordination and suggest that calbindin in these cells is important for differential regulation of calcium signals involved in processing of visual and vestibular information.

\section{LTD at the parallel fiber $\rightarrow$ Purkinje cell synapse}

Calcium release from internal stores by PF-mediated mGluR activation is essential for physiologically relevant forms of LTD at the $\mathrm{PF} \rightarrow$ Purkinje cell synapse, and supralinearity of postsynaptic calcium signals seems to be the prevalent mechanism of coincidence detection that underlies this form of synaptic plasticity (Wang et al., 2000). LTD and its associated behavioral processes are, therefore, likely to be influenced by the action of endogenous calcium-binding proteins. We studied LTD using whole-cell patch-clamp recordings in acute cerebellar slices of Purkinje cellspecific null mutant mice in which postsynaptic effects of calbindin deficiency can be studied independently from presynaptic alterations. The stimulation protocol we applied produces reliable, nearly saturating depression. The same and similar protocols have revealed impaired LTD in other mutant mouse models tested in our and other laboratories (Aiba et al., 1994; Conquet et al., 1994; Kashiwabuchi et al., 1995; De Zeeuw et al., 1998b).

In both control and Purkinje cell-specific null mutant mice, the amplitude of Purkinje cell EPSCs evoked by PF stimulation decreased by $40 \%$ after performing the LTD induction protocol and remained at this level for at least $60 \mathrm{~min}$ (Fig. 4). There were no differences in the time course of depression of EPSCs. These results indicate that the buffering of calcium signals by calbindin is not relevant for induction and maintenance of a form of LTD, which is often impaired in cerebellar mutants. 

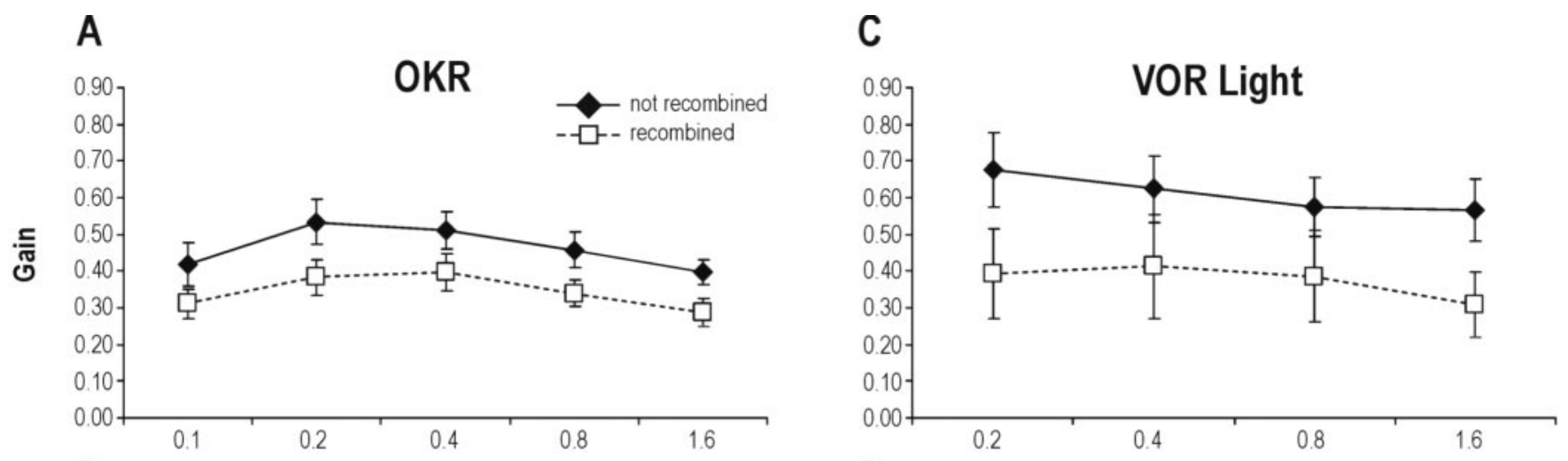

\section{B}
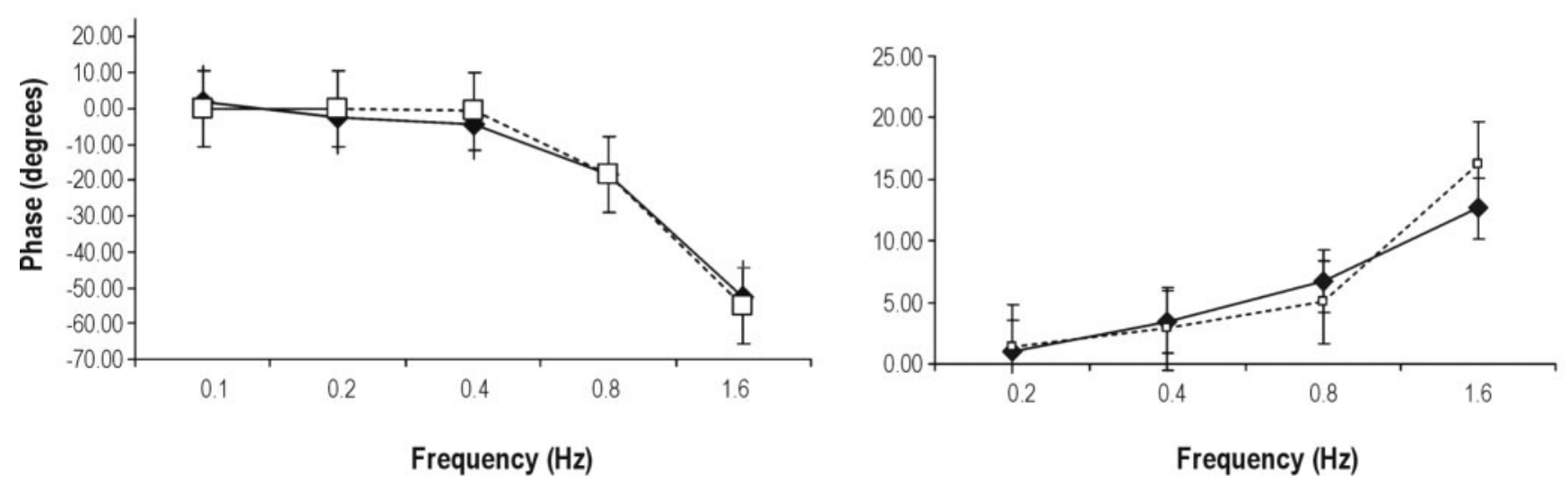

Figure 3. Compensatory eye movements. The gain values of recombined mice $(n=11)$ were significantly smaller than those of the control animals $(n=10)$ during both OKR $(A)$ and VOR-L $(C)$ at all tested frequencies. In contrast, the phase values $(B, D)$ did not differ significantly at any of the frequencies.
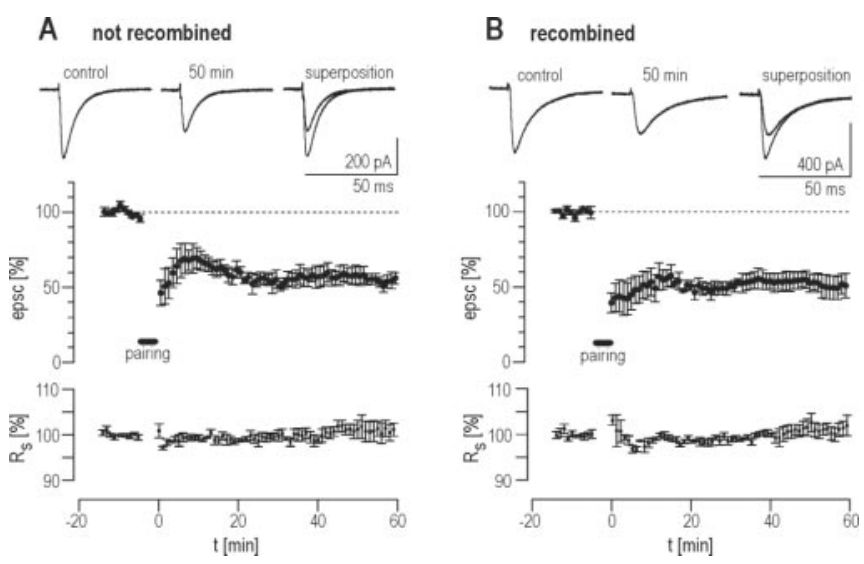

Figure 4. LTD in not-recombined mice $(A)$ and recombined mice $(B)$. Top, PF-EPSCs (average of 12 traces for $A$, a single experiment for $B$ ) recorded 5 min before the start of $L T D$ induction (control) and $50 \mathrm{~min}$ after the end of LTD induction $(50 \mathrm{~min}$ ). The superposition shows the reduction in amplitude after pairing. On average, the pairing protocol induced a reduction of $\sim 40 \%$ in the amplitude of PF-EPSCs in both groups (middle, summary of four experiments; error bars represent SEM). The series resistance (Rs; bottom) remained well within the range of $10 \%$ change compared with the baseline value in all experiments.

\section{Calcium transients evoked by synaptic stimulation}

We measured synaptic calcium transients in spines and adjacent dendrites of Purkinje cells in cerebellar slices (Fig. $5 A, B$ ) using a combination of whole-cell patch-clamp recordings with twophoton imaging. As reported earlier, single-shock PF activation produced fast calcium transients in dendrites and spines because of an AMPA receptor (AMPAR)-mediated local depolarization associated with $\mathrm{Ca}^{2+}$ entry (Eilers et al., 1995). These early synaptic calcium transients (ESCTs) were two to three times larger in amplitude, and their decay time constants were three to four times shorter in recombined than in control animals.

We also investigated synaptic calcium transients elicited by climbing fiber stimulation that results in a standard all-or-none electrical response, the so-called "complex spike" (Llinas and Sugimori, 1980b). Single-shock activation of climbing fibers evoked a complex spike that consisted of a burst of five to six action potentials. As observed earlier (Airaksinen et al., 1997), the electrical responsiveness of the Purkinje neurons was indistinguishable between control and calbindin-deficient mice. Postsynaptic calcium transients were detected throughout the entire dendritic tree and in adjacent dendritic spines. The decay of these calcium transients was best fitted with a monoexponential function (Fig. $5 B, C$ ). Although the electrical response was similar in control and mutant animals, striking differences between the amplitudes and time courses of fast synaptic calcium transients were observed. In mutant mice, peak amplitudes were enhanced by $\sim 80 \%$ in both spines and dendrites, and decay time constants were reduced by $>50 \%$ (Fig. $5 B, C$ ). These data clearly show that calbindin deficiency of Purkinje neurons results in a considerable enhancement and sharpening of fast postsynaptic calcium transients.

To address the question of whether calbindin also affects the amplitude and kinetics of slow postsynaptic calcium signals, a third type of calcium transients that can be evoked by repetitive PF stimulation was investigated (Finch and Augustine, 1998; Takechi et al., 1998). These transients start only $\sim 200 \mathrm{msec}$ after stimulation and peak within $500 \mathrm{msec}$ and were thus termed 
A

Parallel Fibre Stimulation
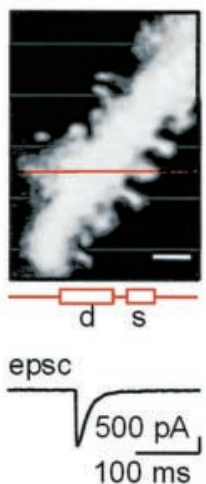

$100 \mathrm{~ms}$

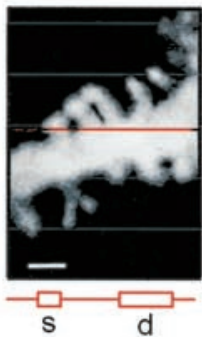

epsc

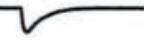

ESCT

wild type

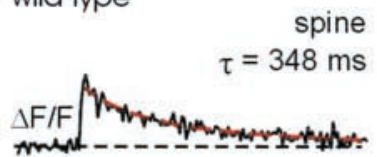

dendrite

$\tau=363 \mathrm{~ms}$

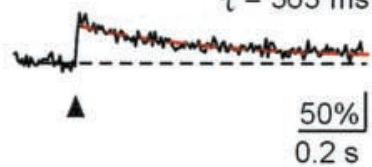

calbindin D28k -/-
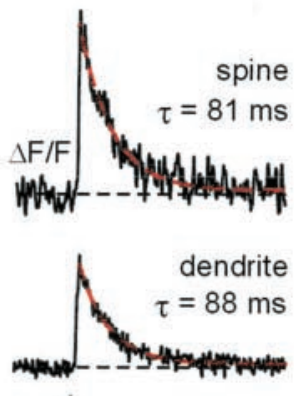

$\Delta$
Early Synaptic Calcium

$T$ ransients (ESCT)

wild type

calbindin D28k -/-

Parallel Fibre Stimulation
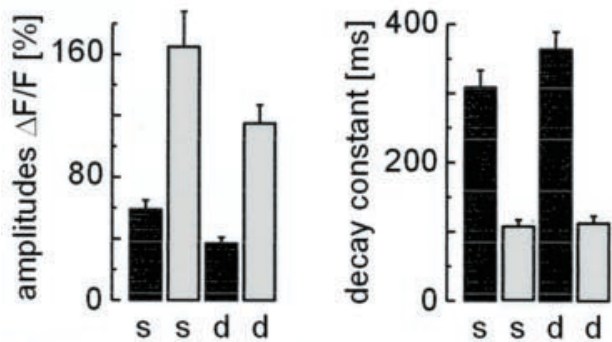

Climbing Fibre Stimulation
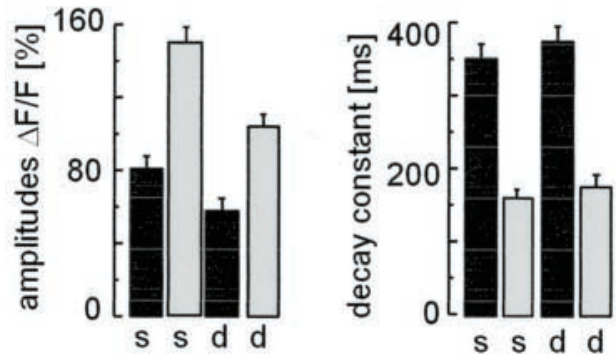

B Climbing Fibre Stimulation
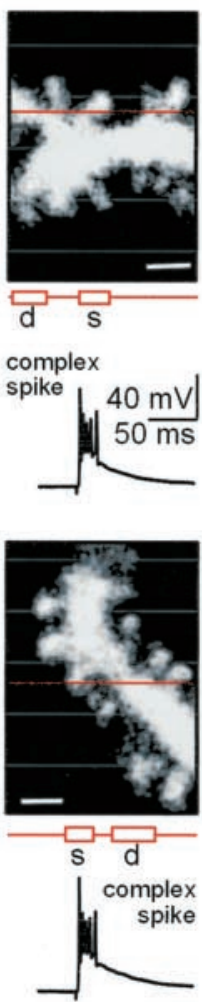

calbindin D28k - -
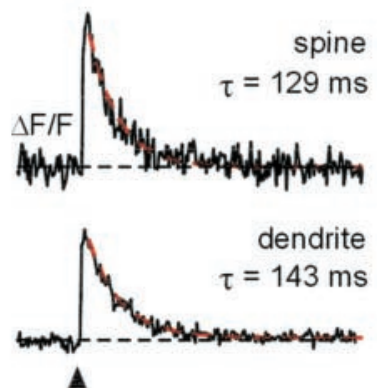

wild type

spine

$\tau=295 \mathrm{~ms}$

dendrite

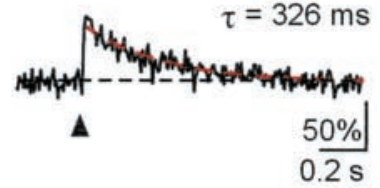

$0.2 \mathrm{~s}$

pine

\section{(1)}

endrite

\section{and}

$\Lambda$

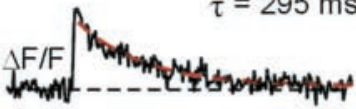
Delayed Synaptic Calcium
Transients (DSCT)
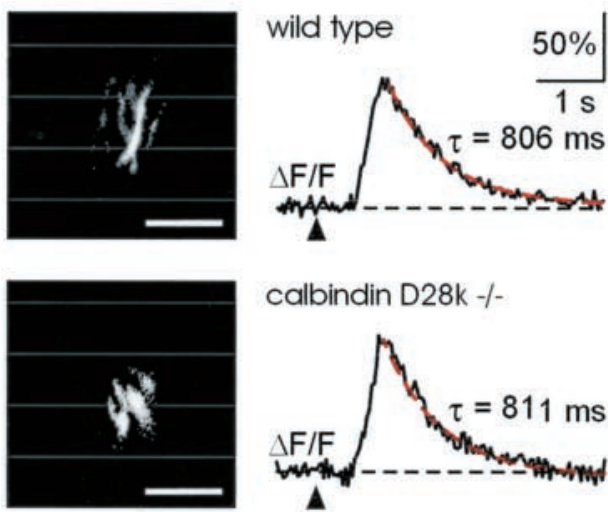

calbindin D28k -/-

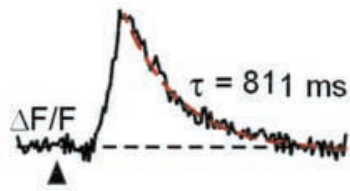

wild type calbindin D28k -/-

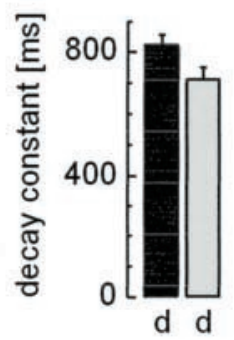

Figure 5. Synaptic $\mathrm{Ca}^{2+}$ signaling. A, Top, Line scan recording of early synaptic calcium transients evoked by single parallel fiber stimulation (ESCT) in a spine and the adjacent dendrite of a not-recombined mouse. Left, Image of the spiny dendrite and the line and regions of interest chosen for the experiment. Scale bar, $1 \mu \mathrm{m}$; d, dendrite; s, spine. Below, Current (EPSC) evoked by parallel fiber stimulation (stimulation intensity, 30 V). Right, ESCT in the spine and the dendrite. Broken red lines represent monoexponential decay functions fitted to the data points. Time constants $(\tau)$ were $348 \mathrm{msec}$ (spine) and $363 \mathrm{msec}$ (dendrite). Bottom, ESCT in a spine and the adjacent dendrite of a recombined mouse. Left (compare with top), Stimulation intensity was $10 \mathrm{~V}$. Right, Despite the smaller EPSC amplitude, ESCT amplitudes were much larger than in the not-recombined animal. Time constants were significantly faster. B, Top, Line scan (Figure legend continues.) 
"delayed synaptic calcium transients" (DSCTs) (Takechi et al., 1998). DSCTs represent $\mathrm{IP}_{3}$-mediated $\mathrm{Ca}^{2+}$ release signals from intracellular stores after activation of mGluRs. Recent work suggests that these are essential for behaviorally relevant forms of LTD at the PF-Purkinje cell synapse (Wang et al., 2000). We analyzed dendritic DSCTs in the presence of the AMPAR antagonist CNQX by means of conventional confocal microscopy and whole-cell patch-clamp recording. In contrast to ESCTs, DSCTs were not significantly altered in recombined mice (Fig. $5 C, D$ ). These data indicate that calbindin selectively buffers only fast synaptically evoked $\mathrm{Ca}^{2+}$ transients, and that it acts close to postsynaptic sites.

\section{Discussion}

Our results directly demonstrate that calbindin expressed in Purkinje cells is an essential determinant of normal motor coordination and sensory integration. The absence of calbindin from this neuron, which exclusively provides an output from the cerebellar cortex, results in a novel mouse phenotype with distinct deficits in the precision of motor coordination and in the processing of coordination-relevant visual information.

The observed deficit is permanent and cannot be fully compensated by learning-related or other plasticity mechanisms. Decreased gain of VOR-L and OKR (both of which of are regulated by visual sensory input) is also observed in the lurcher mouse, a mutant deficient in Purkinje cells (De Zeeuw et al., 1998a). There are, however, clear differences between both mutants in that the phases (i.e., the relative timing of eye movements) were normal in mice lacking calbindin, whereas large alterations in all three experimental paradigms were reported for lurcher mice. This difference may reflect true calbindin-independent phase regulation by Purkinje cells. Furthermore, the gain of the VOR-D is increased in lurcher mice, possibly reflecting secondary plastic changes in the vestibular nuclei because of Purkinje cell loss. Absence of any VOR-D alterations in our mutants suggests that loss of calbindin alone is not sufficient to cause these secondary changes and that the observed behavioral alterations are likely caused by a functional deficit within Purkinje cells.

Differential effects of Purkinje cell-specific calbindin deficiency on visual versus vestibular processing may also be because of recruitment of different extracerebellar brain structures. For example, visually guided limb coordination depends on output from the deep cerebellar nuclei to premotor areas in the cerebral cortex (Passingham et al., 1988; Mushiake and Strick, 1993). In this scenario, genetic changes in all Purkinje cells could invoke differential effects depending on the sensitivity of their extracerebellar targets to altered input from Purkinje cells via the deep cerebellar nuclei.

What are the cellular mechanisms underlying the behavioral malfunction? To assess possible changes in plasticity at this syn- apse, we used a well established model of LTD, which is thought to be behaviorally relevant. The protocol used to induce LTD was comparable with methods previously applied to other mutants (Aiba et al., 1994; Conquet et al., 1994; Kashiwabuchi et al., 1995; De Zeeuw et al., 1998b). Whereas the calcium-binding protein calbindin is highly expressed in Purkinje cells and acts here as a powerful $\mathrm{Ca}^{2+}$ buffer (Fierro and Llano, 1996; Airaksinen et al., 1997; Maeda et al., 1999), and although $\mathrm{Ca}^{2+}$ signaling is essentially needed for the induction process (Sakurai, 1990; Konnerth et al., 1992), LTD is not affected in the Purkinje cell-specific calbindin null mutants. This preservation of LTD is most likely a consequence of the fact that mGluR-mediated $\mathrm{Ca}^{2+}$ signaling, known to be critical for LTD induction (Daniel et al., 1998; Inoue et al., 1998; Wang et al., 2000; Ito, 2001), seems to be normal in the mutant mice. Thus, at least under experimental conditions, the distortion of AMPAR-mediated $\mathrm{Ca}^{2+}$ signals does not significantly hinder LTD induction. We cannot exclude alterations, particularly abnormally enhanced acquisition of LTD, with other LTD protocols, or in other forms of cerebellar synaptic plasticity. Interestingly, a recent report revealed conditions under which postsynaptic, nitric oxide-dependent long-term potentiation (LTP) is observed at the parallel fiber $\rightarrow$ Purkinje cell synapse (Lev-Ram et al., 2002). Because this LTP is enhanced by postsynaptic calcium chelators with properties similar to calbindin, a decrease in its strength might be expected in the Purkinje cellspecific null mutants. However, before comparisons between genotypes are meaningful, the conditions required for this form of LTP need to be firmly established.

In contrast to LTD, kinetics and dynamics of synaptically evoked calcium transients are differentially regulated by calbindin. The explanation for the relative calbindin independency of the slow mGluR-mediated $\mathrm{Ca}^{2+}$ signaling is straightforward. Our recordings of ESCTs in calbindin-deficient mice reveal decay time constants of the calcium signals in the range of $80-100$ msec. These decay time constants are a direct measure of the calciumclearing mechanisms in dendrites in the absence of the dominating fast endogenous calcium buffer. Because the mGluRmediated calcium signal has much slower kinetics, with a time to peak of $>500$ msec and decay time constants in the range of $800-900 \mathrm{msec}$, calcium clearance as well as calcium buffering by calbindin, which prolongs the decay time constant of ESCTs by just 200-300 msec (Fig. 5), will not interfere in a major way with the waveforms of DSCTs. Thus, because calcium mobilization and clearance seem to be the major determinants of the mGluRmediated calcium response, DSCTs were less affected in calbindin-deficient Purkinje cells.

Because calbindin is a rapid endogenous calcium-buffering protein (Roberts, 1993; Airaksinen et al., 1997; Maeda et al., 1999), at least four types of $\mathrm{Ca}^{2+}$ signals can be affected by calbin-

\footnotetext{
$\leftarrow$

(Figure legend continued.) recording of early synaptic calcium transients evoked by climbing fiber stimulation in a spine and the adjacent dendrite of a not recombined mouse. Left (compare with $A$, below), Complex spike evoked by climbing fiber stimulation. Right, Calcium transients in the spine and the dendrite and time constants calculated from monoexponential decay functions (compare with A). Bottom, Calcium transients in a spine and the adjacent dendrite of a recombined mouse. Right, Despite the similar electrical response, amplitudes of calcium transients were much larger than in not recombined animal. Time constants were significantly faster. Calcium transients represent the averages of three consecutive trials; arrowhead indicates the time of synaptic stimulation. $C$, Histograms of ESCT amplitudes and decay time constants in spines (s) and dendrites (d) of not-recombined and recombined animals (parallel fiber stimulation: black bars, $n=21$ dendrites, 30 spines; gray bars, $n=17$ dendrites, 44 spines; climbing fiber stimulation: black bars, $n=11$ dendrites, 26 spines; gray bars, $n=18$ dendrites, 35 spines;). Error bars represent SEM. $D$, mGluR-mediated synaptic calcium signaling. Right, Local dendritic $\mathrm{Ca}^{2+}$ signals mediated by repetitive parallel fiber stimulation (marked by arrowheads, 5 pulses, $50 \mathrm{~Hz}$ ) in the presence of $40 \mu \mathrm{M}$ CNQX. Images demonstrate activated dendritic regions. Scale bars, $20 \mu \mathrm{m}$. Traces show relative changes in fluorescence in regions of interest within these active regions. Broken red lines represent monoexponential decay functions fitted to the data points. Time constants were $806 \mathrm{msec}$ (not recombined) and $811 \mathrm{msec}$ (recombined). Below, Histogram of dendritic decay time constants of the delayed synaptic calcium transients evoked by repetitive parallel fiber stimulation (DSCT) $[n=5$ for not recombined; $n=7$ for recombined; averages are not significantly different ( $t$ test, $p<0.01)]$. Error bars represent SEM.
} 
din deficiency. First, as shown above, the AMPAR-mediated calcium transients produced by parallel fiber stimulation in spines and dendrites are distorted. In spines and the adjacent dendrites, the amplitudes of the $\mathrm{Ca}^{2+}$ transients are enhanced, and the time course is markedly faster. This distortion is predicted by the absence of a rapid $\mathrm{Ca}^{2+}$ buffer (Wagner and Keizer, 1994).

Second, climbing fiber-mediated postsynaptic $\mathrm{Ca}^{2+}$ signals exhibit a similar modification in amplitude and time course in the absence of calbindin (Fig. 5, compare B,C), whereas the electrical responsiveness of the Purkinje cells is apparently not changed. The distortion is observed in dendrites and interestingly also in spines. These results are similar to those described by Airaksinen et al. (1997), who reported amplitude changes that are in the same range. However, whereas the decay phase of synaptic calcium transients was fitted with biexponential functions in the foregoing study, the decay phase of the vast majority of calcium transients analyzed in the present study is best fitted with monoexponential functions. Both the measurement in small compartments and the use of a low dye concentration implicated a reduced signal-to-noise ratio, which might have masked a small additional fast decay time constant. Moreover, Airaksinen et al. found that although the amplitude of the calcium transients was increased in calbindin-deficient mice, the time constants were unchanged (compare Airaksinen et al., 1997, their Figure 4). If the data of Airaksinen et al. (1997) are fitted with only one exponential, the results are identical to those obtained in the present study. We believe that the measurements performed in the present study are more accurate, because we monitored the calcium signals directly at the site of calcium entry. In contrast, the earlier study was performed in thick dendrites relatively close to the cell body.

A third type of $\mathrm{Ca}^{2+}$ signals that might be distorted by calbindin deficiency are action potential-associated $\mathrm{Ca}^{2+}$ transients in the cell bodies (Llinas and Sugimori, 1980a), dendrites (Llinas and Sugimori, 1980b), axons (Callewaert et al., 1996), and terminals. Thus, action potential-evoked $\mathrm{Ca}^{2+}$ transients in dendrites and spines will also have a higher amplitude and a more rapid decay time course and may alter signal integration, perhaps through a reduced efficacy of coincidence detection (Wang et al., 2000).

Finally, transmitter release from Purkinje cell nerve terminals in the deep cerebellar nuclei may be altered. It has been demonstrated that another calcium-binding protein, parvalbumin, regulates the paired-pulse ratio through modulation of transmitter release (Caillard et al., 2000). Furthermore, overexpression or deletion of calbindin in hippocampal neurons resulted in the selective modification of posttetanic potentiation (Chard et al., 1995; Klapstein et al., 1998), presumably by changing the global $\mathrm{Ca}^{2+}$ concentration increase in presynaptic terminals necessary for mediating potentiation of neurotransmitter release on a second to minute time scale.

Thus, although calbindin is absent in only a single, defined cell type in the cerebellum, a wide range of cellular actions involving rapid $\mathrm{Ca}^{2+}$ signaling may contribute to the behavioral deficits.

Our study suggests a new mechanism for an LTDindependent model of cerebellar malfunction caused by the specific deficiency of calbindin in Purkinje cells. Although cerebellar malfunction persisted even after prolonged training, initial rates of improvement of runway performance were similar in calbindin-deficient and control mice, suggesting that some forms of motor learning are intact in the Purkinje cell-specific null mutant. A more rigorous evaluation of motor learning in our mutant by assessment of the adaptability of eye coordination is hindered by their impaired basal eye coordination. Interestingly, different forms of motor learning have been implicated in the phenotype of another Purkinje cell-specific mutant with normal basal eye coordination and impaired LTD (De Zeeuw et al., 1998b; Goossens et al., 2001). Animals with reduced PKC activity are severely impaired in short-term but much less so in long-term adaptability of eye movements. This has led to the hypothesis that LTD may be more important for short-term motor learning (van Alphen and De Zeeuw, 2002). The situation in calbindin-deficient mice seems complementary: normal LTD with normal initial performance improvement is combined with long-term deficits. Thus, rapid $\mathrm{Ca}^{2+}$ signaling regulated by endogenous $\mathrm{Ca}^{2+}$ buffering proteins such as calbin-din might contribute to longterm learning involving as yet unknown cellular targets and pathways.

It needs to be stressed that rapid $\mathrm{Ca}^{2+}$ signaling, for example in association with action potential firing, is a general property of all central neurons. A large variety of endogenous calciumbinding proteins control the dynamics of rapid intracellular $\mathrm{Ca}^{2+}$ signals in a highly cell type-specific manner. Therefore, the impact of our results may extend far beyond Purkinje cell and cerebellar function, indicating a widespread role of rapid $\mathrm{Ca}^{2+}$ signaling in neuronal computation.

\section{References}

Aiba A, Kano M, Chen C, Stanton ME, Fox GD, Herrup K, Zwingman TA, Tonegawa S (1994) Deficient cerebellar long-term depression and impaired motor learning in mGluR1 mutant mice. Cell 79:377-388.

Airaksinen MS, Eilers J, Garaschuk O, Thoenen H, Konnerth A, Meyer M (1997) Ataxia and altered dendritic calcium signaling in mice carrying a targeted null mutation of the calbindin D28k gene. Proc Natl Acad Sci USA 94:1488-1493.

Barski JJ, Dethleffsen K, Meyer M (2000) Cre recombinase expression in cerebellar Purkinje cells. Genesis 28:93-98.

Barski JJ, Morl K, Meyer M (2002) Conditional inactivation of the calbindin D-28k (Calb1) gene by Cre/loxP-mediated recombination. Genesis 32:165-168.

Caillard O, Moreno H, Schwaller B, Llano I, Celio MR, Marty A (2000) Role of the calcium-binding protein parvalbumin in short-term synaptic plasticity. Proc Natl Acad Sci USA 97:13372-13377.

Callewaert G, Eilers J, Konnerth A (1996) Axonal calcium entry during fast 'sodium' action potentials in rat cerebellar Purkinje neurones. J Physiol (Lond) 495:641-647.

Celio MR (1990) Calbindin D-28k and parvalbumin in the rat nervous system. Neuroscience 35:375-475.

Chard PS, Jordan J, Marcuccilli CJ, Miller RJ, Leiden JM, Roos RP, Ghadge GD (1995) Regulation of excitatory transmission at hippocampal synapses by calbindin D28k. Proc Natl Acad Sci USA 92:5144-5148.

Conquet F, Bashir ZI, Davies CH, Daniel H, Ferraguti F, Bordi F, Franz-Bacon K, Reggiani A, Matarese V, Conde F (1994) Motor deficit and impairment of synaptic plasticity in mice lacking mGluR1. Nature 372:237-243.

Daniel H, Levenes C, Crepel F (1998) Cellular mechanisms of cerebellar LTD. Trends Neurosci 21:401-407.

De Zeeuw CI, van Alphen AM, Koekkoek SK, Buharin E, Coesmans MP, Morpurgo MM, van den BJ (1998a) Recording eye movements in mice: a new approach to investigate the molecular basis of cerebellar control of motor learning and motor timing. Otolaryngol Head Neck Surg 119:193-203.

De Zeeuw CI, Hansel C, Bian F, Koekkoek SK, van Alphen AM, Linden DJ, Oberdick J (1998b) Expression of a protein kinase C inhibitor in Purkinje cells blocks cerebellar LTD and adaptation of the vestibulo-ocular reflex. Neuron 20:495-508.

Eilers J, Augustine GJ, Konnerth A (1995) Subthreshold synaptic $\mathrm{Ca}^{2+}$ signalling in fine dendrites and spines of cerebellar Purkinje neurons. Nature 373:155-158.

Fierro L, Llano I (1996) High endogenous calcium buffering in Purkinje cells from rat cerebellar slices. J Physiol (Lond) 496:617-625.

Finch EA, Augustine GJ (1998) Local calcium signalling by inositol-1,4,5trisphosphate in Purkinje cell dendrites. Nature 396:753-756. 
Goossens J, Daniel H, Rancillac A, van der SJ, Oberdick J, Crepel F, De Zeeuw CI, Frens MA (2001) Expression of protein kinase C inhibitor blocks cerebellar long-term depression without affecting Purkinje cell excitability in alert mice. J Neurosci 21:5813-5823.

Gorcs TJ, Penke B, Boti Z, Katarova Z, Hamori J (1993) Immunohistochemical visualization of a metabotropic glutamate receptor. NeuroReport 4:283-286.

Ichise T, Kano M, Hashimoto K, Yanagihara D, Nakao K, Shigemoto R, Katsuki M, Aiba A (2000) mGluR1 in cerebellar Purkinje cells essential for long-term depression, synapse elimination, and motor coordination. Science 288:1832-1835.

Inoue T, Kato K, Kohda K, Mikoshiba K (1998) Type 1 inositol 1,4,5trisphosphate receptor is required for induction of long-term depression in cerebellar Purkinje neurons. J Neurosci 18:5366-5373.

Ito M (1986) Long-term depression as a memory process in the cerebellum. Neurosci Res 3:531-539.

Ito M (2001) Cerebellar long-term depression: characterization, signal transduction, and functional roles. Physiol Rev 81:1143-1195.

Kano M, Hashimoto K, Watanabe M, Kurihara H, Offermanns S, Jiang H, Wu Y, Jun K, Shin HS, Inoue Y, Simon MI, Wu D (1998) Phospholipase cbeta4 is specifically involved in climbing fiber synapse elimination in the developing cerebellum. Proc Natl Acad Sci USA 95:15724-15729.

Kashiwabuchi N, Ikeda K, Araki K, Hirano T, Shibuki K, Takayama C, Inoue Y, Kutsuwada T, Yagi T, Kang Y (1995) Impairment of motor coordination, Purkinje cell synapse formation, and cerebellar long-term depression in GluR delta 2 mutant mice. Cell 81:245-252.

Klapstein GJ, Vietla S, Lieberman DN, Gray PA, Airaksinen MS, Thoenen H, Meyer M, Mody I (1998) Calbindin-D28k fails to protect hippocampal neurons against ischemia in spite of its cytoplasmic calcium buffering properties: evidence from calbindin-D28k knockout mice. Neuroscience 85:361-373.

Koekkoek SK, Alphen AM, vd BJ, Grosveld F, Galjart N, De Zeeuw CI (1997) Gain adaptation and phase dynamics of compensatory eye movements in mice. Genes Funct 1:175-190.

Konnerth A, Llano I, Armstrong CM (1990) Synaptic currents in cerebellar Purkinje cells. Proc Natl Acad Sci USA 87:2662-2665.

Konnerth A, Dreessen J, Augustine GJ (1992) Brief dendritic calcium signals initiate long-lasting synaptic depression in cerebellar Purkinje cells. Proc Natl Acad Sci USA 89:7051-7055.

Lev-Ram V, Wong ST, Storm DR, Tsien RY (2002) A new form of cerebellar long-term potentiation is postsynaptic and depends on nitric oxide but not cAMP. Proc Natl Acad Sci USA 99:8389-8393.

Llinas R, Sugimori M (1980a) Electrophysiological properties of in vitro Purkinje cell somata in mammalian cerebellar slices. J Physiol (Lond) 305:171-195.

Llinas R, Sugimori M (1980b) Electrophysiological properties of in vitro Purkinje cell dendrites in mammalian cerebellar slices. J Physiol (Lond) 305:197-213.

Maeda H, Ellis-Davies GC, Ito K, Miyashita Y, Kasai H (1999) Supralinear
$\mathrm{Ca}^{2+}$ signaling by cooperative and mobile $\mathrm{Ca}^{2+}$ buffering in Purkinje neurons. Neuron 24:989-1002.

Martin LJ, Blackstone CD, Huganir RL, Price DL (1992) Cellular localization of a metabotropic glutamate receptor in rat brain. Neuron 9:259-270.

Matsumoto M, Nakagawa T, Inoue T, Nagata E, Tanaka K, Takano H, Minowa O, Kuno J, Sakakibara S, Yamada M, Yoneshima H, Miyawaki A Fukuuchi Y, Furuichi T, Okano H, Mikoshiba K, Noda T (1996) Ataxia and epileptic seizures in mice lacking type 1 inositol 1,4,5-trisphosphate receptor. Nature 379:168-171.

Mikoshiba K, Furuichi T, Miyawaki A (1994) Structure and function of IP3 receptors. Semin Cell Biol 5:273-281.

Miyata M, Finch EA, Khiroug L, Hashimoto K, Hayasaka S, Oda SI, Inouye M Takagishi Y, Augustine GJ, Kano M (2000) Local calcium release in dendritic spines required for long-term synaptic depression. Neuron 28:233-244.

Mushiake H, Strick PL (1993) Preferential activity of dentate neurons during limb movements guided by vision. J Neurophysiol 70:2660-2664.

Offermanns S, Hashimoto K, Watanabe M, Sun W, Kurihara H, Thompson RF, Inoue Y, Kano M, Simon MI (1997) Impaired motor coordination and persistent multiple climbing fiber innervation of cerebellar Purkinje cells in mice lacking Gaq. Proc Natl Acad Sci USA 94:14089-14094.

Passingham RE, Myers C, Rawlins N, Lightfoot V, Fearn S (1988) Premotor cortex in the rat. Behav Neurosci 102:101-109.

Pochet R, Pasteels B, Seto-Ohshima A, Bastianelli E, Kitajima S, Van Eldik LJ (1991) Calmodulin and calbindin localization in retina from six vertebrate species. J Comp Neurol 314:750-762.

Roberts WM (1993) Spatial calcium buffering in saccular hair cells. Nature 363:74-76

Rose CR, Konnerth A (2001) Stores not just for storage. Intracellular calcium release and synaptic plasticity. Neuron 31:519-522.

Ryo Y, Miyawaki A, Furuichi T, Mikoshiba K (1993) Expression of the metabotropic glutamate receptor mGluR1 alpha and the ionotropic glutamate receptor GluR1 in the brain during the postnatal development of normal mouse and in the cerebellum from mutant mice. J Neurosci Res 36:19-32.

Sakurai M (1990) Calcium is an intracellular mediator of the climbing fiber in induction of cerebellar long-term depression. Proc Natl Acad Sci USA 87:3383-3385.

Scotti AL (1995) Calbindin D28k in the olivocerebellar projection. A light and electron microscopic study. J Anat 187:649-659.

Takechi H, Eilers J, Konnerth A (1998) A new class of synaptic response involving calcium release in dendritic spines. Nature 396:757-760.

van Alphen AM, De Zeeuw CI (2002) Cerebellar LTD facilitates but is no essential for long-term adaptation of the vestibulo-ocular reflex. Eur J Neurosci 16:486-490.

Wagner J, Keizer J (1994) Effects of rapid buffers on $\mathrm{Ca} 2+$ diffusion and Ca2 + oscillations. Biophys J 67:447-456.

Wang SS, Denk W, Hausser M (2000) Coincidence detection in single dendritic spines mediated by calcium release. Nat Neurosci 3:1266-1273. 